\title{
Driving ability in sleep apnoea patients before and after CPAP treatment: evaluation on a road safety platform
}

\author{
S. Mazza*,\#, J-L. Pépin**\#, B. Naëgelé*,\#, E. Rauch**\#, C. Deschaux", \\ P. Ficheux ${ }^{+}$and P. Lévy*,\#
}

ABSTRACT: Sleepiness is considered to be the major cause of increased traffic accidents in patients with obstructive sleep apnoea syndrome (OSAS). Until now, OSAS patients' driving ability has been assessed using driving simulators, but no assessment in a more natural driving environment has been carried out to date.

The aim of the present study was to evaluate driving parameters in OSAS and in controls on a road safety platform, and to compare them with attentional in-laboratory measures before and after continuous positive airway pressure treatment.

The parameters measured were: reaction time; distance to stop and number of collisions on the platform; maintenance of wakefulness; and sustained, selective and divided attention in laboratory.

Patients exhibited much longer reaction times than controls, leading to a lengthening of the vehicle's stopping distance of $8.8 \mathrm{~m}$ at $40 \mathrm{~km} \cdot \mathrm{h}^{-1}$ and to twice the number of collisions. Patients did not demonstrate objective sleepiness or selective and sustained attention deficits. Divided attention deficits were found. However, they did not allow the prediction of real driving impairment. After CPAP treatment, there was no longer any difference between patients and controls regarding driving and attention performances.

Driving abilities are significantly impaired in obstructive sleep apnoea syndrome. After continuous positive airway pressure treatment, deficits were normalised. This stresses the importance of evaluating attentional parameters in apnoeic patients and of offering continuous positive airway pressure treatment even to non-sleepy subjects.

KEYWORDS: Attention, driving performance, reaction time, sleep apnoea

$\mathrm{n}$ recent years, concern regarding motorvehicle accidents related to sleepiness has increased. In France, the national road safety agency estimated that in 2003 one out of four fatal highway accidents was directly related to sleepiness.

Several risk factors for the occurrence of sleepiness at the wheel exist, including long periods of wakefulness, time of day, alcohol and drug consumption, work hours, reduced sleep time, and sleep disorders resulting in excessive daytime sleepiness, such as obstructive sleep apnoea syndrome (OSAS).

OSAS is a common and underestimated sleep disorder affecting $\sim 4 \%$ of middle-aged males [1]. This syndrome is characterised by repeated complete (apnoea) or partial (hypopnoea) collapses of the upper airway during sleep. These events cause micro-arousals and nocturnal oxygen desaturation thought to be responsible for sleep fragmentation and excessive daytime sleepiness.

Retrospective studies, based on subjective and objective records, have shown that the rate of traffic accidents among drivers with sleep apnoea is increased by two to seven times compared with non-apnoeic drivers [2-4]. However, even if most of the evidence suggests that OSAS leads to an increased risk when driving, these results have been criticised based on epidemiological and methodological considerations [5] and interindividual susceptibility [6].

Studies assessing the relationship between excessive sleepiness and accidents have shown conflicting results for both subjective and objective tests $[1-3,7,8]$. These results could be explained
AFFILIATIONS

*HP2 laboratory (hypoxia pathophysiology) INSERM ERI 0017 Joseph Fourier University, Grenoble, \#Sleep Laboratory, EFCR, Grenoble University Hospital, Grenoble,

"Agir à dom, Meylan, and

+Minotaure Road Platform, Voreppe, France.

CORRESPONDENCE

S. Mazza

Sleep Laboratory

EFCR

Grenoble University Hospital

BP 217

38043 Grenoble Cedex 09

France

Fax: 33476765586

E-mail: smazza@wanadoo.fr

Received:

September 282005

Accepted after revision:

June 292006

SUPPORT STATEMENT

Grants from Regional Research Council (DRRC 2003, CHU de

Grenoble, France) and Scientific

Council of Agir à Dom 2003.

Online ISSN 1399-3003 
by the multiple consequences of sleepiness on driving performance. Impairment of vigilance does not necessarily suppose sleeping episodes, but does include more subtle attentional deteriorations, such as increased informationprocessing and decision-making time, increased reaction time to critical events, less effective control responses and decreased readiness to meet danger [9]. The United States National Accident Sampling System (NASS) data reported by GEORGE [10] support the implication of inattention in road accidents, by reporting that $61 \%$ of drowsy drivers were found to have taken no avoidance action prior to their collision. These data suggest that sleepiness may significantly contribute to a diminished driving performance. However, the author also pointed out that inattentiveness, without definite episodes of falling asleep, could lead to a diminished driving performance.

Several studies using driving simulators have demonstrated altered reaction time and related psychomotor performances in apnoeic patients $[11,12]$. Performances of many, but not all, sleep apnoea patients during these tasks have been shown to be worse than that of controls under the influence of alcohol $[13,14]$. After treatment with continuous positive airway pressure (CPAP), performance on simulators improved $[15,16]$ and the number of motor-vehicle crashes seemed to return to normal [17-19].

However, even if some authors showed a relationship between performances using driving simulators and real road accidents $[17,20]$, in-laboratory measurements do not allow assessment of the complexity of real driving performances [19]. Driving simulators are useful tools, but their measurements are limited to controlled and simplified environments. Moreover, it remains unclear if driving-simulator performance or deficits on other laboratory-based performance tests translate appropriately to real driving difficulty in OSAS.

The objective of the current project was to evaluate the performance of a group of apnoeic patients and a group of control subjects on a road safety platform. The present study also aimed to compare the performances obtained on this platform to those obtained in the laboratory using psychometric tools assessing wakefulness and attention. Patients were also evaluated after 3 months of CPAP treatment in order to establish the treatment impact on their driving performance.

\section{METHODS}

\section{Population studied}

Twenty patients with OSAS (18 males and two females) and 20 non-obese and non-snoring control subjects (17 males and three females), matched for age, educational level, and number of years of driving were included in the present study. OSAS patients had been referred to the authors' institution for clinical suspicion of sleep-disordered breathing. They were recruited in the Sleep Laboratory where they underwent polysomnography (PSG). Controls were healthy volunteers, recruited by advertisements in local newspapers and in the hospital. They had no medical history, did not complain of any symptom of sleep disorders and exhibited a normal Epworth sleepiness scale (ESS) score. They were naïve to the experiment. The absence of OSAS was further confirmed using a portable device allowing home monitoring of respiration during sleep.
Subjects with history of neurological or psychiatric disease, chronic lung disease, uncorrected visual or auditive impairment, chronic sedative intake or alcohol abuse were excluded. Also, subjects with significant cognitive impairment or depression (score $<23$ out of 30 at the Mini Mental State Examination [21] and Beck Depression Inventory II score $>19$ [22]) were excluded. All the participants had possessed a driving licence for $\geqslant 15$ yrs and were regular drivers.

Ten OSAS patients agreed to participate in the same evaluation 3 months after CPAP treatment. The 10 matched control subjects were also re-evaluated 3 months later, in order to control for the learning effect. CPAP compliance was measured by mask-pressure monitoring and expressed as the time spent at the therapeutic pressure.

The study was approved by the institutional ethics committee. None of the participants, including the control subjects, received any financial compensation for their participation in the study.

\section{Polysomnography}

Details of the PSG techniques utilised herein have been published elsewhere [23]. Studies were scored using standard techniques and criteria [24, 25]. Micro-arousals ending respiratory events were called respiratory-related micro-arousals.

The portable device (HypnoPTT ${ }^{\circledR}$; Tyco Healthcare, Villers-lesNancy, France) used for normal subjects included a combination of sensors, i.e. nasal cannula, oximeter, pulse transit time and body position, allowing identification of the number of respiratory events, their obstructive or central nature and the occurrence of sleep fragmentation using the detection of autonomic arousals by pulse transit time.

\section{Driving on the road safety platform, vigilance and attention assessment}

The evaluations of vigilance, attention and driving performance were performed on two mornings, starting at 09:00 h, during the week following PSG recording. Sleep quality is likely to be subjectively comparable to that on the nights preceding the tests. These two evaluations allowed measurement of the attention capacities in real driving on the one hand and the attention capacities in the laboratory on the other hand. The order of these evaluations was randomised.

\section{Driving performances}

The driving performances were evaluated on a road safety platform called Minotaure, which is usually dedicated to selfevaluation of driving ability. This platform is made up of two separate one-way tracks (one in each direction), being $150 \mathrm{~m}$ long and $3 \mathrm{~m}$ wide. The platform is fitted with digital cameras and magnetic detectors, and enables the recording of several parameters during an emergency braking task. A central automaton records and compiles these parameters. Once the vehicle hit the track at the required speed, the automaton propelled a jet of water forming an aquatic obstacle of $1.5 \mathrm{~m}$ high and $2 \mathrm{~m}$ wide (fig. 1). The occurrence of the jet was calculated according to the vehicle's speed and its position on the track, in order to appear at an average distance of $40 \mathrm{~m}$ in front of the vehicle, without the subject being able to anticipate its occurrence and its location. The subjects were instructed 


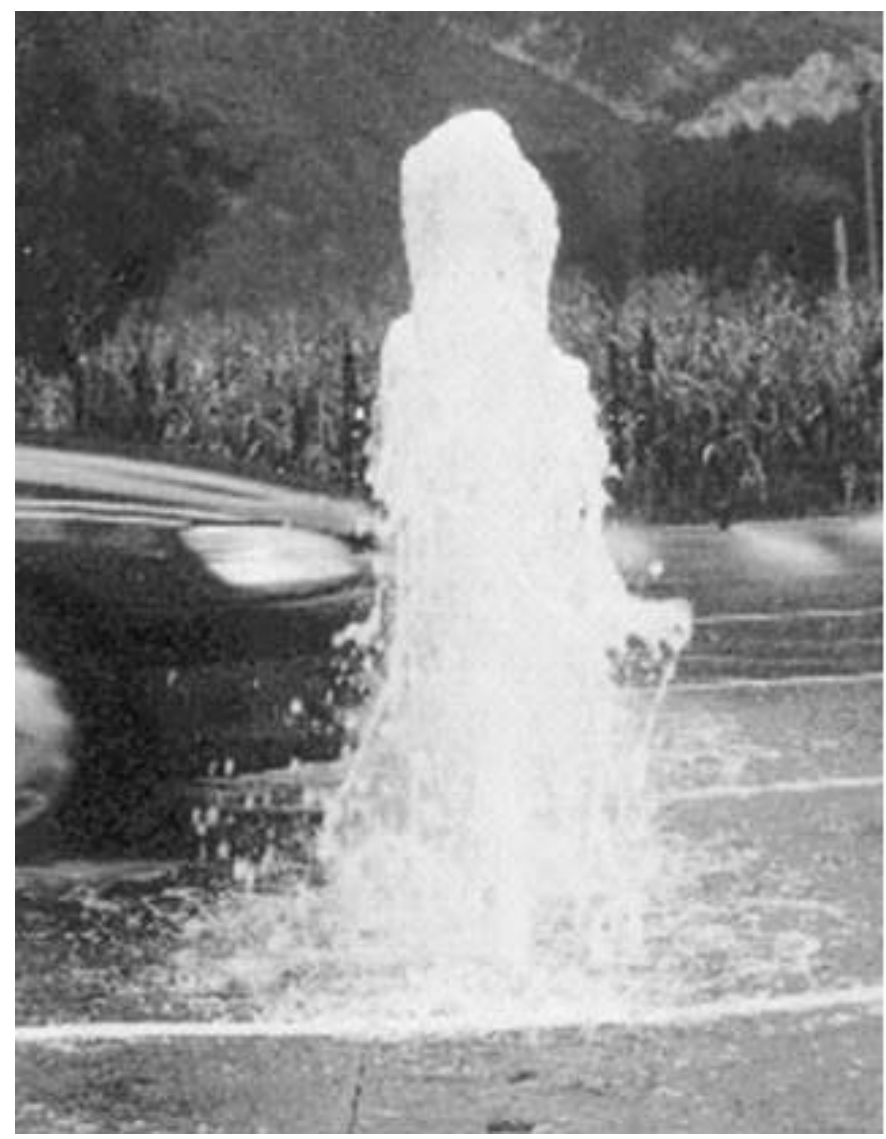

FIGURE 1. Aquatic obstacle display on the road platform.

that as soon as the obstacle was visible, they had to stop their vehicle as quickly as possible in order to avoid impact.

The magnetic detectors covering the track inform the automaton about the vehicle's position and allow the deduction of its speed. The digital cameras capture the appearance of the vehicle's brake lights and allow the calculation of a reaction time, defined as the interval of time between the appearance of the aquatic obstacle and the vehicle's brake lights coming on. A stopping distance is measured as the distance covered between the time of occurrence of the aquatic obstacle and the immobilisation of the vehicle.

The driving task consisted of avoiding an aquatic obstacle during three real driving conditions: 1) simple condition; 2) distraction condition; and 3) anticipation condition.

For each of these tests, the participants were alone in the vehicle and on the track. The examiner, who was a road safety expert, could communicate with the drivers by radio during the test. The examiner was unaware of the subject status (OSAS patients versus controls). In each condition, the subject had to reach and maintain a speed of $40 \mathrm{~km} \cdot \mathrm{h}^{-1}$. This was verified by the examiner during the tests.

During the simple condition, no specific manoeuvre was required before braking.

The distraction condition was set in order to reproduce a condition during which the driver's attention was not solely focused on driving. During this situation an action on the vehicle commands was required at the moment when the aquatic obstacle appeared. The order was given orally by the examiner via the radio at the exact time the water was programmed to be propelled. This was chosen at random among three options: switch on the windscreen wipers, the signal lights or the hazard-warning lights. This action had to be carried out before the vehicle stopped.

The last condition consisted of anticipating braking by asking the subject to keep their foot above the braking pedal as soon as they reached the speed of $40 \mathrm{~km} \cdot \mathrm{h}^{-1}$, in order to anticipate the appearance of the aquatic obstacle. This condition was designed to evaluate the effect of anticipation on braking and to reduce motor execution time from the reaction time. This trial was thus designed to provide a more accurate estimate of the attention processes involved in the total reaction time.

The parameters studied were as follows: reaction time to the nearest $0.1 \mathrm{~s}$; stopping distance; number of collisions; number of actions which were carried out correctly during the distraction situation; and vehicle speed.

The same vehicle was used for each of the participants and was equipped with new tyres, assisted steering and antilock braking system (ABS) brakes. It was also equipped with a manual gearshift. Each condition trial consisted of making a complete return trip, following the same instructions. The trials were preceded with an acclimatisation phase, which consisted of two return trips. The total duration of the driving task did not exceed $30 \mathrm{~min}$. Before each test the instructions were repeated to the subject via the radio. The results presented are averaged data obtained from the return trips for each of the conditions.

\section{Vigilance and attention assessment in laboratory}

All subjects performed three different vigilance tests in a random order, at 09:00 h: the Oxford sleep resistance (OSleR) test (Stowood Scientific Instruments, Oxford, UK), which assesses the ability to remain awake during a soporific task (modified maintenance of wakefulness test); the Continuous Performance Test (CPT; Multi-Health Systems, Toronto, Canada) which assesses sustained and selective attention; and the Driving Simulator Test (Stowood Scientific Instruments), which measures divided attention capacities. Subjects were instructed on how to perform each of the tests, which took place in a quiet and darkened room.

\section{Maintenance of wakefulness during a soporific task: the OSleR test}

The OSleR test corresponds to a 40-min sleep-resistance challenge, measuring maintenance of wakefulness during a soporific task. The test procedure has been detailed in a previous article [26]. The data collected from the OSleR test were the sleep latencies (duration of the test) and the number of omissions (non-responses to stimuli) during the test.

\section{Sustained and selective attention: the CPT}

The CPT assesses the ability to detect and to respond to specified stimulus changes occurring infrequently and at random intervals over $20 \mathrm{~min}$, while simultaneously inhibiting responses to stimuli. 
The subject monitors a continuous presentation of letters on a computer screen. The subject is instructed to react by pressing the space bar each time a letter appears (targets) except when the letter $X$ is presented, in which case, they must not respond (non-targets). Non-responses to targets are recorded as omissions and inappropriate response to non-targets as commissions.

The data obtained from this test are the number of omissions, commissions, the mean reaction time (response latency) and attentiveness $\left(D^{\prime}\right)$, which is a measure of how well the individual discriminates between targets and non-targets.

\section{Divided attention: driving simulator}

This divided attention test requires participants to steer a car moving on a winding road while simultaneously performing a visual target detection. A computer-based image of the moving edges of a pseudo-randomly winding road is portrayed white on black. An image of the front of the car is portrayed at the bottom of the screen. The subject steers (using a computer steering wheel) the centre of the vehicle as accurately as possible down the middle of the road for $20 \mathrm{~min}$. Single numbers, 1-9, appear randomly at each corner of the screen and change every $10 \mathrm{~s}$. The divided attention part of the test is that the subject, while steering the car, has to scan the four corners of the screen, identify the target digit (number 2) each time it appears, and react by pressing a button on either side of the steering wheel. If the subject does not respond within $10 \mathrm{~s}$ of the target number, the number changes and an omission has occurred. The test ends after $20 \mathrm{~min}$ or before if the car leaves the road for a continuous period of more than $15 \mathrm{~s}$. Prior to the test, a training session was given.

The data collected included the duration of the test, the mean reaction time (perception of target numbers) and the number of "off-road" events (when the centre of the bonnet crosses the road's edges) quoted per hour of driving.

\section{Statistical analysis}

Values are expressed as mean \pm SD. Normality of distribution was checked using Kurtosis and Skewness test. An unpaired ttest or Mann-Whitney test was used to compare control and patient groups on quantitative variables. Chi-squared tests

\begin{tabular}{|c|c|c|c|}
\hline $\begin{array}{ll}\text { TABLE } 1 & \text { Characteristics } \\
\text { syndrome and }\end{array}$ & $\begin{array}{l}\text { the obstru } \\
\text { trol grour }\end{array}$ & ive sleep & pnoea \\
\hline Variable & Patients & Controls & p-values \\
\hline Subjects $n$ & 20 & 20 & \\
\hline Age yr & $54.1 \pm 5.9$ & $52.2 \pm 8.3$ & NS \\
\hline $\mathrm{BMI} \mathrm{kg} \cdot \mathrm{m}^{-2}$ & $28.9 \pm 4.9$ & $24.3 \pm 2.7$ & $<0.01$ \\
\hline RDI & $44.4 \pm 13$ & $4.5 \pm 3.9$ & $<0.001$ \\
\hline Mean nocturnal $\mathrm{O}_{2}$ sat $\%$ & $93.9 \pm 1.0$ & $96.0 \pm 0.8$ & $<0.001$ \\
\hline Time spent with $\mathrm{O}_{2}$ sat $<90 \%$ min & $2.9 \pm 4.5$ & 0 & $<0.001$ \\
\hline Epworth Sleepiness Scale & $11.4 \pm 3.4$ & $8.4 \pm 2.7$ & 0.02 \\
\hline
\end{tabular}

were used for qualitative variables. Paired t-tests or their nonparametric equivalents, Wilcoxon tests, were carried out depending on the variables' distribution. Correlation analyses were carried out using Spearman tests. Regarding multiplicity of comparisons, a multiple contrast correction (Bonferroni) was applied, within three independent attentional tests (OSleR test, CPT test and driving simulator) and three driving conditions (simple, distraction and anticipation condition).

\section{RESULTS}

Table 1 shows the subjects' characteristics and sleep study results for the OSAS and control groups.

\section{Measurements before treatment: first evaluation}

Vigilance and attentional assessment in laboratory

Table 2 summarises the results obtained in the vigilance tests for the control and patient groups.

The initial attention evaluation in the OSleR test showed identical average sleep latencies for maintaining wakefulness for patients and control subjects. Only a significant difference in the number of errors could be demonstrated.

No significant inter-group difference was observed for the set of selective and sustained attention variables (CPT test).

The driving simulator test showed significantly deteriorated performances for the apnoeic group compared with the control group. OSAS patients had a longer reaction time in response to target numbers and had more off-road events than controls. The test duration was also shorter in the OSAS group compared to the control group because of earlier off-road events $>15 \mathrm{~s}$ duration in the patient group.

\section{Driving performance on the road safety platform}

Results are presented for each driving condition. In order to verify the impact of each condition, reaction time obtained in the anticipation and distraction conditions during this baseline session have been compared to reaction time of the simple evaluation.

The performances obtained at the first evaluation on the road platform are summarised in table 3 . For all driving conditions, the speed on this platform did not differ between the two groups or between the different conditions (mean speed: $39.9 \pm 2.6$ versus $40.1 \pm 2.2 \mathrm{~km} \cdot \mathrm{h}^{-1}$ for patients and controls respectively).

The data show significantly longer reaction times for patients compared with controls for each of the three driving conditions. On average, the reaction times of the apnoeic patients were $0.5 \mathrm{~s}$ slower than those of the control subjects $(1.6 \pm 0.2$ versus $1.1 \pm 0.3$ s respectively, $\mathrm{p}<0.001$ ).

During the simple driving conditions, the lengthening of the reaction time for the apnoeic patients was also accompanied by a lengthening of the vehicle's stopping distance when compared with the control group. The number of collisions with the aquatic obstacle was higher for the patients but not to a significant level.

The distraction condition caused a lengthening of the reaction times in both groups $(1.77 \pm 0.34$ versus $1.51 \pm 0.35 \mathrm{~s}$ in patients, $\mathrm{p}=0.049 ; 1.24 \pm 0.48$ versus $0.91 \pm 0.21 \mathrm{~s}$ in controls, $\mathrm{p}=0.005)$. 
TABLE 2 Vigilance and attentional assessment

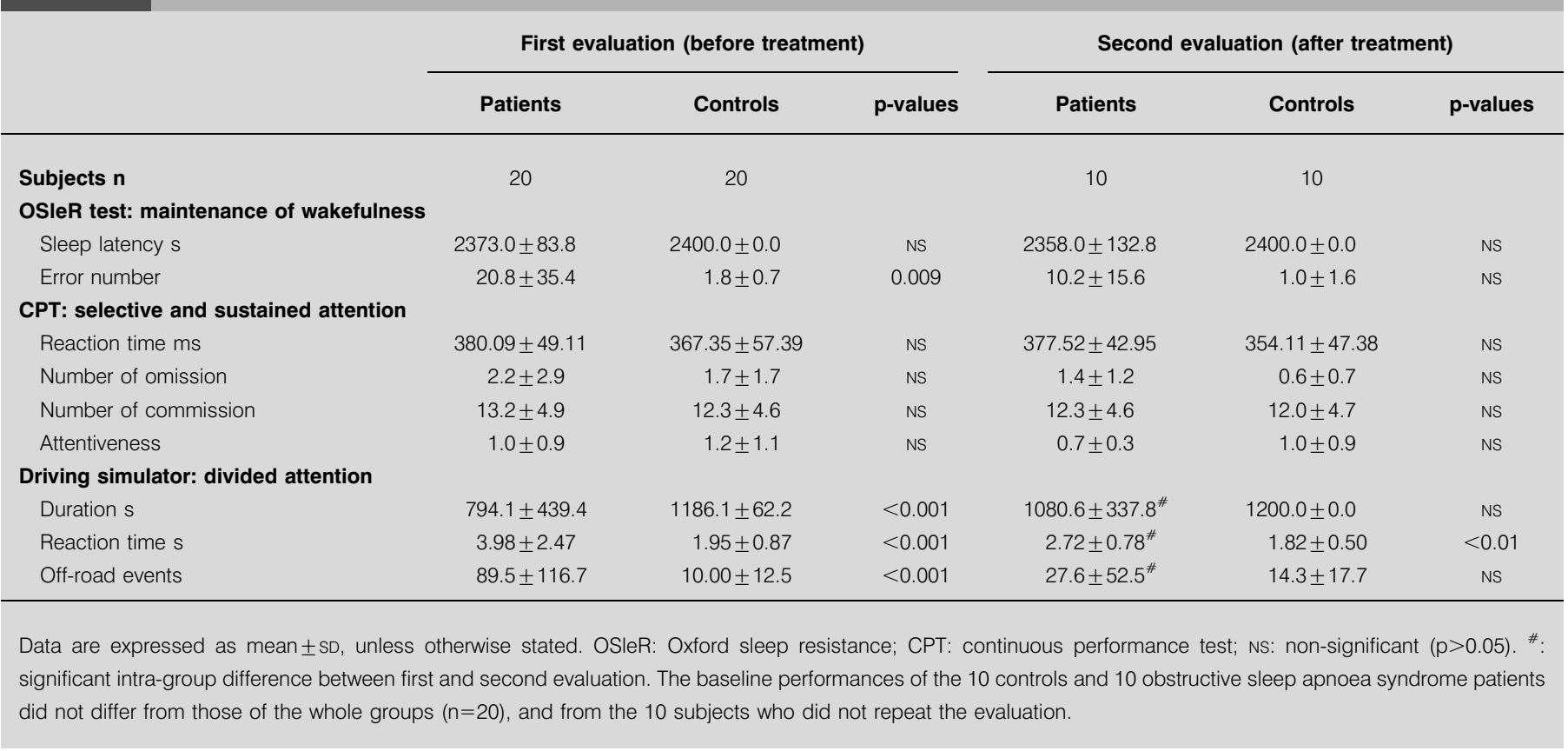

However, the reaction times for the apnoeic subjects remained significantly different from those of the control subjects. The braking distance, the number of actions correctly performed and the number of collisions did not differ between the two groups.

In the distraction condition, the control subjects demonstrated an increased stopping distance when compared with the simple driving condition ( $38.0 \pm 4.5$ versus $27.9 \pm 6.5 \mathrm{~m}, \mathrm{p}=0.0002)$ while there was no further increase in the apnoeic patients.
The braking-anticipation condition did not lead to any improvement in reaction times when compared with the simple situation for either group. In this condition, however, the patients still exhibited significantly reduced driving performance when compared to controls (table 3).

An association was found between the mean reaction time in real driving condition and reaction time in the divided attention test (driving simulator) $(\mathrm{r}=0.46, \mathrm{p}=0.003$; fig. 2 ). However, the relationship did not allow the prediction of

TABLE 3 Driving performances of obstructive sleep apnoea syndrome patients and controls

\begin{tabular}{|c|c|c|c|c|c|c|}
\hline & \multicolumn{3}{|c|}{ First evaluation (before treatment) } & \multicolumn{3}{|c|}{ Second evaluation (after treatment) } \\
\hline & Patients & Controls & p-values & Patients & Controls & p-values \\
\hline Subjects $n$ & 20 & 20 & & 10 & 10 & \\
\hline \multicolumn{7}{|c|}{ Simple condition of driving } \\
\hline Reaction time s & $1.51 \pm 0.35$ & $0.91 \pm 0.21$ & $<0.001$ & $0.99 \pm 0.22^{\#}$ & $1.06 \pm 0.13^{\#}$ & NS \\
\hline \multicolumn{7}{|c|}{ Distraction condition of driving } \\
\hline Reaction time $s$ & $1.77 \pm 0.34$ & $1.24 \pm 0.48$ & $<0.001$ & $1.14 \pm 0.32^{\#}$ & $1.22 \pm 0.31$ & NS \\
\hline Distance to stop $\mathrm{m}$ & $38.65 \pm 6.0$ & $37.4 \pm 4.5$ & NS & $31.6 \pm 3.2^{\#}$ & $34.0 \pm 3.6$ & NS \\
\hline Number of collisions & $0.8 \pm 0.7$ & $0.7 \pm 0.7$ & NS & $0.4 \pm 0.7$ & $0.3 \pm 0.5$ & NS \\
\hline Actions & $1.1 \pm 0.8$ & $1.6 \pm 0.5$ & NS & $1.2 \pm 0.6$ & $1.7 \pm 0.5$ & NS \\
\hline \multicolumn{7}{|c|}{ Anticipation condition of driving } \\
\hline
\end{tabular}

Data are expressed as mean $\pm \mathrm{SD}$, unless otherwise stated. All driving-performance tests were carried out at $40 \mathrm{~km} \cdot \mathrm{h}^{-1} \mathrm{NS}$ : non-significant $(\mathrm{p}>0.05) .{ }^{\#}:$ significant intragroup difference between first and second evaluation. 


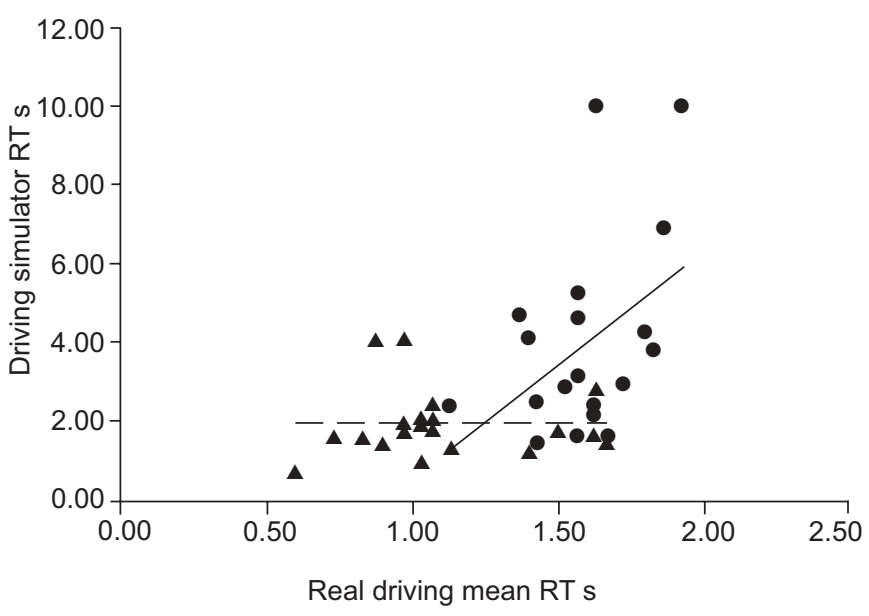

FIGURE 2. Correlation between reaction times (RT), during driving simulator and real driving. $\bullet$ : obstructive sleep apnoea syndrome (OSAS) patients $(p=0.05$, $r=0.43) ; \mathbf{\Lambda}$ : control subjects $(p=0.79, r=0.06)$. Correlation for the whole group $p=0.003, r=0.46$. — : regression line for OSAS patients; --- : regression line for control subjects.

individual values for real driving reaction times. No other associations were found between attentional in-laboratory measures and real driving condition performance. There was no correlation between performance at any of the attentional tests or during the real driving conditions and the ESS score, or any sleep variable measured.

\section{Measurements after CPAP treatment: second evaluation}

Tables 2 and 3 show the performance of the 10 apnoeic subjects and 10 controls during the second evaluation in the laboratory and on the platform. The baseline performance of these 10 controls and 10 OSAS patients did not differ from those of the whole groups $(n=20)$, and from the 10 subjects who did not repeat the evaluation. This was true for the in-laboratory tests, the driving performance on the platform and also for the PSG variables measured.

Vigilance and attentional assessment in laboratory

The performances for the OSleR and CPT tests, obtained for the two subgroups of subjects $(n=10)$ were not different from those obtained for the same subjects during the preceding evaluation or from those of the whole groups $(n=20)$. Patients and the controls did not differ in sleep latency and number of errors in the OSleR test. The reaction time, number of errors and attentiveness marks for the CPT did not differ between the patients and the controls (table 2). The patients exhibited significantly different scores in the driving simulator test after treatment in comparison with their baseline values. The length of the test was significantly longer during the second evaluation $(698.7 \pm 420.8$ versus $1080.6 \pm 337.8 \mathrm{~s}, \mathrm{p}=0.02)$, the reaction times decreased but were not significantly shorter $(4.1 \pm 2.5$ versus $2.7 \pm 0.8 \mathrm{~s})$, and the number of off-road events was fewer $\left(72.7 \pm 85.2\right.$ versus $\left.27.6 \pm 52.5 \cdot \mathrm{h}^{-1}, \mathrm{p}=0.01\right)$. The performance of the control subjects did not differ from that obtained during the first evaluation. After treatment, the scores of the patients did not differ from those of the control subjects, except for the reaction time that was still higher in apnoeic patients for this test.

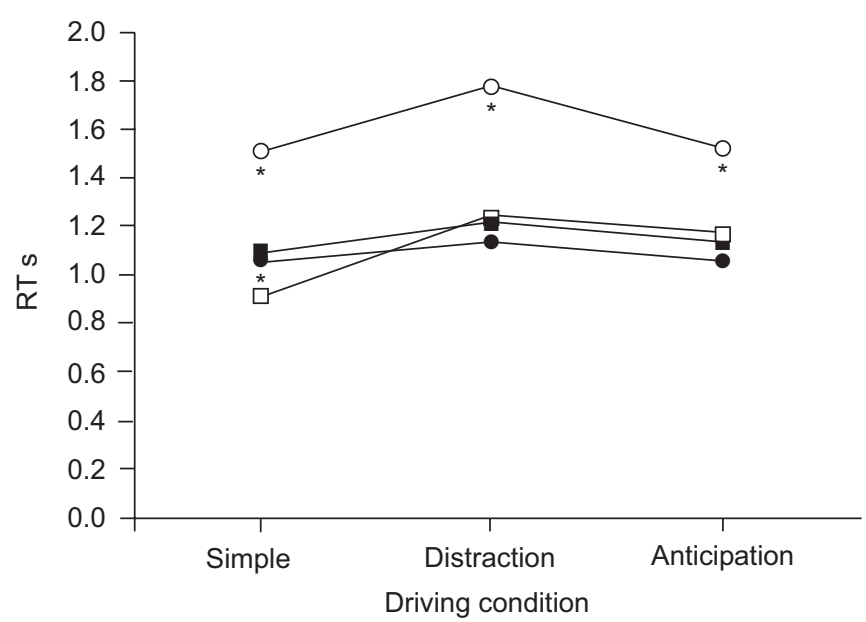

FIGURE 3. Comparison of reaction times (RT) between the first and second evaluations for the two groups. $\bigcirc$ : patients first evaluation; $\square$ : controls first evaluation; - patients second evaluation; $\mathbf{\square}$ : controls second evaluation. *: significant difference between first and second evaluations, $p<0.05$.

\section{Driving performance on the road safety platform}

The performance of the control group did not differ from that of these same subjects during the first evaluation. Only the reaction time of the simple driving condition appeared significantly longer during this second evaluation in comparison with baseline $(1.06 \pm 0.16$ versus $0.96 \pm 0.16 \mathrm{~s}, \mathrm{p}=$ 0.004). No learning effect could be perceived from these results.

After treatment with CPAP, the average reaction times for each of the conditions were significantly lower in apnoeic patients when compared to baseline (mean reaction time: $1.08 \pm 0.22$ versus $1.56 \pm 0.13 \mathrm{~s}, \mathrm{p}<0.0001$; fig. 3 ).

The patients also demonstrated a significant reduction in their stopping distance compared with baseline, for both the distraction and anticipation driving conditions (31.6 \pm 3.2 after treatment versus $36.9 \pm 4.9 \mathrm{~m}$ before treatment; and $33.7 \pm 6.8$ versus $43.7 \pm 9.3 \mathrm{~m}$ respectively, $\mathrm{p}=0.03$ ).

During simple driving, the reduction obtained did not reach statistical significance $(28.4 \pm 7.3 \mathrm{~m}$ after treatment versus $32.0 \pm 4.1 \mathrm{~m})$.

When comparing the post-treatment performance in patients to the second evaluation in controls, there was no significant difference in reaction times, stopping distance, number of collisions and actions in any of the driving conditions.

The reaction times, stopping distances and number of collisions did not differ when comparing the simple driving condition, the distraction condition or the anticipation condition, for any group.

\section{DISCUSSION}

This is the first study evaluating the consequences of OSAS and the impact of its treatment on driving performance using the more natural driving environment of a road safety platform. 
Before treatment, apnoeic patients demonstrated a major slowing in their reaction times behind the wheel, especially when the driving context required emergency braking to be applied.

The average reaction times for OSAS patients were $0.5 \mathrm{~s}$ slower than those of the control subjects. This means that these patients needed $0.5 \mathrm{~s}$ longer than control subjects to analyse the situation and to start braking. Making the assumption that the vehicle's speed is unlikely to alter the reaction time, this implies that at $130 \mathrm{~km} \cdot \mathrm{h}^{-1}$, the maximum speed authorised on highways in France, the patients would have covered $18 \mathrm{~m}$ more than the control subjects before beginning to brake when urgently needed. This latency period could explain why, in the US NASS, a large proportion of somnolent subjects implicated in traffic accidents do not attempt any avoidance action before collision [27].

The present results have been observed on a road safety platform where all risks were controlled. The participants were warned about the behaviour they would have to adopt and their attention was directly focused on the obstacle. The short duration of the test $(30 \mathrm{~min})$ limits the potential influence of other factors on driving performance. As a consequence, this test represents an advantageous driving situation for subjects with attentional deficits who are more sensitive to prolonged and soporific tasks. Nevertheless, despite this favourable and stimulating context, OSAS patients exhibited decreased driving abilities. In real life, there are often other factors that may indeed add to the difficulty of the task and which may vary on a day-to-day basis: driving at night or under sleep deprivation, alcohol or sedative intake, inadequate speed and driving errors. These additional factors are likely to reduce driving performance even more in patients already exhibiting attentional difficulties.

A complete attentional battery was conducted in the present study in order to compare in-laboratory testing and real driving abilities. Although the patient selection was made at random among patients referred to the sleep clinic, they did not show any objective deficit of maintenance of wakefulness. This was demonstrated by the normal sleep latencies during the OSleR test. However, the higher number of errors in this test compared to controls demonstrated a significant attention reduction, without sleepiness. An attentional deficit was also observed during the divided attention test (driving simulator). These results confirm and extend what the current authors have previously shown in another group of patients suffering from attentional deficits without objective sleepiness [28]. The divided attention test (or driving simulator) appeared to be a useful tool to assess attentional abilities in apnoeic patients. However, although there was a correlation between reaction times measured during driving simulator and driving on the platform respectively, the driving simulator did not allow for accurate prediction of driving impairment on an individual basis. None of the other attentional tests performed in the present study, i.e. PSG measures or ESS score, showed any association with performance on the road safety platform. In a recent study, ORTH et al. [19] also failed to find any association between neuropsychological assessment and driving abilities. The current authors share with ORTH et al. [19] the hypothesis that driving is a complex task which may not be entirely predicted by a simple neuropsychological test. Nevertheless, the driving simulator provides meaningful clinical results and allows treatment evaluation in a more accessible manner than real-life driving assessment.

The results of the present study also show a major improvement in performance after CPAP treatment. Treating patients who do not manifest subjective somnolence has been questioned [29]. There is strong evidence in the literature showing a cognitive benefit during CPAP treatment for OSAS patients $[15,30]$, as well as an improvement in their quality of life [31], and a reduction in traffic accidents $[2,3,16]$. However, most of these data have been issued from clinical studies on patients with perceived sleepiness or loss of vigilance. The results obtained in the current study demonstrate the benefit of treating apnoeic patients without objective somnolence, as it seems to improve their attention level when driving and thus their driving performances.

On the road safety platform, different driving conditions were used during this experiment. The distracted driving situation enabled demonstration of how carrying out a particular action interferes with driving performance. During this condition there was a significant increase in the reaction times and stopping distances of both control subjects and patients. However, the increase in reaction times in the apnoeic subjects was less marked than in the control group. This could be explained by a ceiling effect in the apnoeic subjects, owing to saturation of their attentional system during the simple driving condition. The correlation observed in patients between the driving simulator and the platform results supports this hypothesis. For apnoeic subjects, the attention required in real driving conditions could be comparable to what was required in this double-task situation. Actually, the patients exhibited difficulties at the wheel that could be similar to those found during the driving simulator, both requiring division of their attention between several pieces of information to be processed simultaneously.

The anticipation condition did not show the expected reduction in reaction times in comparison with the simple situation. During this condition, patients were asked to position their foot above the brake pedal before the occurrence of the aquatic obstacle, in order to anticipate braking. The discomfort caused by this unusual driving situation could partly explain why the reaction times were not shortened in this condition in comparison with the simple condition. In the anticipation condition, it was expected that the motor part of the reaction time would presumably be reduced because the participants were positioned for braking before the obstacle appeared. However, this condition was more complicated than expected, and the controls' performances reached performances of OSAS patients.

Overall, these results demonstrate a significant impairment in the driving ability of apnoeic patients. In comparison to the pre-existing data in the literature, the present study provides two major additional pieces of information. First, this is now shown using a road-safety scenario. The duration of driving was limited, which, by definition, does not allow important factors such as the soporific effects of long-distance driving to be taken into account. However, it was sufficient 
to demonstrate a significant impairment. This strongly suggests that driving ability in less-controlled conditions is likely to be even worse.

Second, it is now shown that treatment with CPAP leads to normal reaction times and driving performance in OSAS patients. The novelty of this finding is not only based on the direct assessment of CPAP effects on real-life driving, it also demonstrates that this benefit was evidenced in patients without objective somnolence. In improving their attentional deficits, CPAP also normalised the driving performance of these patients. This should be taken into account when selecting treatment for OSAS patients, even in those without a significant objective sleepiness.

In conclusion, even though they had no difficulty maintaining wakefulness during in-laboratory evaluation, obstructive sleep apnoea syndrome patients exhibited a reduction in their driving ability. This is due to attentional deficits that are likely to increase reaction times and braking distances. In daily life, driving ability is presumably worse owing to the impact of soporific conditions on vigilance, a factor that was not evaluated during the present study. Continuous positive airway pressure treatment was effective in normalising driving ability in these patients and should be considered even when sleepiness is not obvious. Public health policy should take into account the impact of obstructive sleep apnoea syndrome on driving ability in order to reduce traffic accidents. There are presently simple strategies that could be used in order to detect attentional deficits and reduction in driving ability besides the clinical symptoms. More work is needed to further validate some of these strategies.

\section{ACKNOWLEDGEMENTS}

The authors would like to thank C. Loiodice, M. Selek and Minotaure's instructors for their technical assistance. The authors are also indebted to D. Petit for her helpful editorial suggestions.

\section{REFERENCES}

1 Young T, Palta M, Dempsey J, Skatrud J, Weber S, Badr S. The occurrence of sleep-disordered breathing among middle-aged adults. N Engl J Med 1993; 328: 1230-1235.

2 Teran-Santos J, Jimenez-Gomez A, Cordero-Guevara J. The association between sleep apnea and the risk of traffic accidents. Cooperative Group Burgos-Santander. N Engl J Med 1999; 340: 847-851.

3 Young T, Blustein J, Finn L, Palta M. Sleep-disordered breathing and motor vehicle accidents in a populationbased sample of employed adults. Sleep 1997; 20: 608-613.

4 Barbe F, Pericas J, Munoz A, Findley L, Anto JM, Agusti AG. Automobile accidents in patients with sleep apnea syndrome. An epidemiological and mechanistic study. Am J Respir Crit Care Med 1998; 158: 18-22.

5 Connor J, Whitlock G, Norton R, Jackson R. The role of driver sleepiness in car crashes: a systematic review of epidemiological studies. Accid Anal Prev 2001; 33: $31-41$.
6 George CF. Sleep. 5: Driving and automobile crashes in patients with obstructive sleep apnoea/hypopnoea syndrome. Thorax 2004; 59: 804-807.

7 Masa JF, Rubio M, Findley LJ. Habitually sleepy drivers have a high frequency of automobile crashes associated with respiratory disorders during sleep. Am J Respir Crit Care Med 2000; 162: 1407-1412.

8 Aldrich MS. Automobile accidents in patients with sleep disorders. Sleep 1989; 12: 487-494.

9 George CFP. Driving simulators in clinical practice. Sleep Med Rev 2003; 7: 311-320.

10 George CF. Vigilance impairment: assessment by driving simulators. Sleep 2000; 23: Suppl. 4, S115-S118.

11 Findley LJ, Suratt PM, Dinges DF. Time-on-task decrements in "steer clear" performance of patients with sleep apnea and narcolepsy. Sleep 1999; 22: 804-809.

12 Juniper M, Hack M, George CFP, Davies RJO, Stradling JR. Steering simulation performance in patients with sleep apneoa and matched control subjects. Eur Respir J 2000; 15: 590-595.

13 George CF, Boudreau AC, Smiley A. Comparison of simulated driving performance in narcolepsy and sleep apnea patients. Sleep 1996; 19: 711-717.

14 Powell NB, Riley RW, Schechtman KB, Blumen MB, Dinges DF, Guilleminault C. A comparative model: reaction time performance in sleep-disordered breathing versus alcohol-impaired controls. Laryngoscope 1999; 109: 1648-1654.

15 Engleman HM, Martin SE, Deary IJ, Douglas NJ. Effect of continuous positive airway pressure treatment on daytime function in sleep apnoea/hypopnoea syndrome. Lancet 1994; 343: 572-575.

16 Hack M, Davies RJ, Mullins R, et al. Randomised prospective parallel trial of therapeutic versus subtherapeutic nasal continuous positive airway pressure on simulated steering performance in patients with obstructive sleep apnoea. Thorax 2000; 55: 224-231.

17 Findley L, Unverzagt M, Guchu R, Fabrizio M, Buckner J, Suratt P. Vigilance and automobile accidents in patients with sleep apnea or narcolepsy. Chest 1995; 108: 619-624.

18 George CF. Reduction in motor vehicle collisions following treatment of sleep apnoea with nasal CPAP. Thorax 2001; 56: 508-512.

19 Orth M, Duchna HW, Leidag M, et al. Driving simulator and neuropsychological testing in OSAS before and under CPAP therapy. Eur Respir J 2005; 26: 898-903.

20 Turkington PM, Sircar M, Allgar V, Elliott MW. Relationship between obstructive sleep apnoea, driving simulator performance, and risk of road traffic accidents. Thorax 2001; 56: 800-805.

21 Folstein MF, Folstein SE, McHugh PR. "Mini-Mental State": a practical method for grading the cognitive state of patients for the clinician. J Psychiatr Res 1975; 12: 189-198.

22 Beck AT, Sterr RA, Brown GK. BDI-II manual. San Antonio: The Psychological Corporation, 1996.

23 Argod J, Pepin JL, Smith RP, Levy P. Comparison of esophageal pressure with pulse transit time as a measure of respiratory effort for scoring obstructive nonapneic respiratory events. Am J Respir Crit Care Med 2000; 162: 87-93.

24 American Academy of Sleep Medicine Task Force, Sleeprelated breathing disorders in adults: recommendations for 
syndrome definition and measurement techniques in clinical research. Sleep 1999; 22: 667-689.

25 Sleep Disorders Atlas Task Force of the American Sleep Disorders Association, EEG arousals: Scoring rules and examples. Sleep 1992; 15: 173-184.

26 Mazza S, Pepin J-L, Deschaux C, Naegele B, Levy P. Analysis of error profiles occurring during the OSLER test - a sensitive mean of detecting fluctuations in vigilance in patients with obstructive sleep apnea syndrome. Am J Respir Crit Care Med 2002; 166: 474-478.

27 Sussman ED, Bishop H, Madnick B, Walter R. Driver inattention and highway safety. Transportation Research Record 1985; 1047: 40-48.

28 Mazza S, Pepin JL, Naegele B, Plante J, Deschaux C, Levy P. Most obstructive sleep apnoea patients exhibit vigilance and attention deficits on an extended battery of tests. Eur Respir J 2005; 25: 75-80.

29 Barbe F, Mayoralas LR, Duran J, et al. Treatment with continuous positive airway pressure is not effective in patients with sleep apnea but no daytime sleepiness. A randomized, controlled trial. Ann Intern Med 2001; 134: 1015-1023.

30 Naegele B, Pepin JL, Levy P, Bonnet C, Pellat J, Feuerstein $C$. Cognitive executive dysfunction in patients with obstructive sleep apnea syndrome (OSAS) after CPAP treatment. Sleep 1998; 21: 392-397.

31 Sanner BM, Klewer J, Trumm A, Randerath W, Kreuzer I, Zidek W. Long-term treatment with continuous positive airway pressure improves quality of life in obstructive sleep apnoea syndrome. Eur Respir J 2000; 16: 118-122. 